\title{
Endoscopic Sinus Surgery Decision and Timing for Endodontic Origin Sinusitis After Failure of Primary Medical Treatment
}

\author{
Ibrahim Eldsoky $^{1^{*}}$ MD; Wael Fawzy Ismaiel Essa ${ }^{2}$ MD; Ahmed Abd AL Rahman Mahmoud ${ }^{2}$ MD; \\ Nashwa Mostafa Elsayed ${ }^{3}$ Msc
}

\section{*Corresponding Author: \\ Ibrahim Eldsoky \\ ibrahimeldsokyorl@gmail.com}

Received for publication December 2,2020;Accepted january 23, 2021; Published online january 23, 2021.

\section{Copyright 2020 The Authors published by Al-Azhar University, Faculty of Medicine, Cairo, Egypt. All rights reserved. This an open-access article distributed under the legal terms, where it is permissible to download and share the work provided it is properly cited. The work cannot be changed in anyway or used commercially.}

doi: 10.21608/aimj.2021.51956.1367

${ }^{1}$ Otorhinolaryngology Department Faculty of medicine, Al-Azhar university, Cairo, Egypt.

${ }^{2}$ Otorhinolaryngology Department Faculty of medicine, Al-Azhar university, Damietta, Egypt.

${ }^{3}$ Dentistry Department, El-Hussein university hospital, Cairo, Egypt.

\begin{abstract}
Background: Odontogenic sinus disease requires optimal management, which includes definitive management of the underlying dental pathology. Additional endodontic management of root canal, dental extraction, or apicoectomy. So, in patients who have failed initial medical and/or dental therapy, endoscopic sinus surgery (ESS) is recommended. However, the optimal timing for ESS is still unclear in literatures.

Objective: to find the optimal time for ESS in patients with odontogenic sinusitis (ODS) after the failure of the primary medical treatment.

Patients and methods: This research was performed on 25 ODS patients: 14 males and 11 females. After the failure of primary medical treatment, these patients had preferred and undergone ESS. Another 21 patients who had dental intervention were used for comparison (12 females and 9 males). Assessment of the outcome was performed by the Sino-nasal Outcome Test-22 (SNOT-22) questionnaire for all patients.

Results: The patients improved as there is a decrease in SNOT-22 score from $38.75 \pm 9.56$ to $15.7 \pm 18.12$ in ESS group ( $\mathrm{p}=0.000$ ), more than dental group that decreased from $37.93 \pm 11.3$ to $28.42 \pm 21.7(\mathrm{p}=$ 0.039 ). It was observed that the SNOT-22 score increased as the time of intervention increased, so it is advised to start ESS as early as possible to have a successful surgery.

Conclusion: An early ESS of ODS is a clue for a fast and successful treatment outcome. So, it is recommended that primary ESS is first to be performed, particularly in patients sufferings severe unresolved sinusitis, followed by dental treatment, which is the ideal protocol for management of ODS.
\end{abstract}

Keywords: Endodontic-origin maxillary sinusitis, odontogenic sinusitis, endoscopic sinus surgery, maxillofacial CT, sinusitis of dental origin.

Disclosure: The authors have no financial interest to declare in relation to the content of this article. The Article Processing Charge was paid for by the authors.

Authorship: All authors have a substantial contribution to the article.

\section{INTRODUCTION}

Odontogenic or endodontic sinusitis is defined as the presence of sinus disease with dental origin diagnosed radiographically, microbiologically and/or clinically. ${ }^{1}$ Approximately $10 \%$ of sinusitis diseases are of dental origin (odontogenic), with several literature reports mentioning the underlying dental disease in up to $40 \%$ of instances of nasal sinusitis. ${ }^{2}$ Dental surgery was responsible for many chronic sinusitis patients increased every year. ${ }^{3}$ Increased rates of oro-dental surgery in past years may be related to an increased occurrence of iatrogenic triggers of sinusitis in a previous study. ${ }^{4}$

Symptoms of nasal congestion face pain or pressure, nasal dripping, purulent rhinorrhea (unilateral), bad odor or taste, feeling hot, and fatigue are usually included in the clinical presentation. Patients may report a recent dental intervention. A thorough oro- dental history is mandatory. ${ }^{1}$ However, latency duration of at least one year for sinusitis correlated with augmentative dental surgery and a latency of almost four years for sinusitis correlated with implants. 5

Two-dimensional (2D) high-resolution periapical radiography allows for the identification of dental caries and periapical radiolucency. A 2D presentation of the curved surfaces of the sinuses is provided by panoramic radiography. The size of periapical lesions, cystic lesions, and sinus floor mucosal thickening can be determined by this modality. ${ }^{1}$ Both imaging modalities record a high rate of false negative. One study stated that the missed periapical radiography was of $60 \%$ of periodontal disease relative to CT cone beam. ${ }^{6}$ 
Maxillofacial CT allows for a detailed evidence of paranasal sinus anatomy and sinonasal diseases. Thus, the gold standard for the assessment of the paranasal sinus and its related diseases is considered to be this modality. ${ }^{7}$

Oral antibiotics alone are insufficient for ODS, but can temporarily enhance symptoms before conducting final dental or surgical interventions. ${ }^{8}$ Besides dental and medical treatment, ESS might be needed, especially for patients with medical and dental treatment that has failed. ${ }^{9}$

Both dental intervention and endoscopic sinus surgery were required in a limited number of literatures. The predictive factors of the need for endoscopic sinus surgery were further established by Mattos et al. ${ }^{10}$.

In this study, we try to clear the choices of treatment and optimal timing for ESS intervention and the role of dentists in patients with odontogenic sinusitis.

\section{PATIENTS AND METHODS}

This prospective study started following the failure of the patients' primary medical treatment in both groups (endoscopic sinus surgery group and dental procedure group) and it was conducted on 25 ODS patients (group 1) diagnosed by computed tomography (CT). They were 14 males and 11 females, treated by ESS. Another 21 ODS patients (12 females and 9 males) treated by dental procedure (group 2) used for comparison with ESS patients. They were referred to our department for treatment of sinusitis. The study was performed in the Otorhinolaryngology departments and Dentistry departments of Al-Azhar University Hospital, Damietta, El-Hussein University Hospital, Cairo, Egypt from July 2016 to January 2020. With follow up period of six months for all patients of both groups after definitive treatment.

Patients gave written informed consent for their clinical records to be included in this research. The Institutional Review Board (IRB) approval was obtained from Al-Azhar University Hospitals for this study.

The participants in the research were adults over 18 years of age who had sinusitis of dental orange (figure 1). The exclusion criteria were for those who had sinusitis other than dental origin such as pansinusitis or nasal polyps.

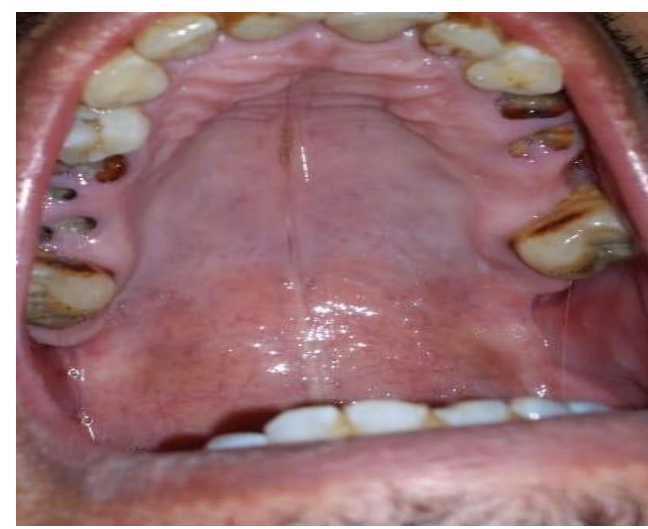

Fig. 1: Showing upper right and left remaining roots due to severe dental caries and bad oral hygiene
Diagnosis of ODS is dependent on a comprehensive investigation. Assessment of patient symptoms \{according to the criteria of the American Academy of Otolaryngology-Head and Neck Surgery (AAOHNS), diagnosis of rhinosinusitis includes at minimum 2 major factors or at minimum 1 major and 2 minor factors of a set of clinical signs and symptoms \}, dental history, paranasal sinus CT or cone-beam CT (figure 2).

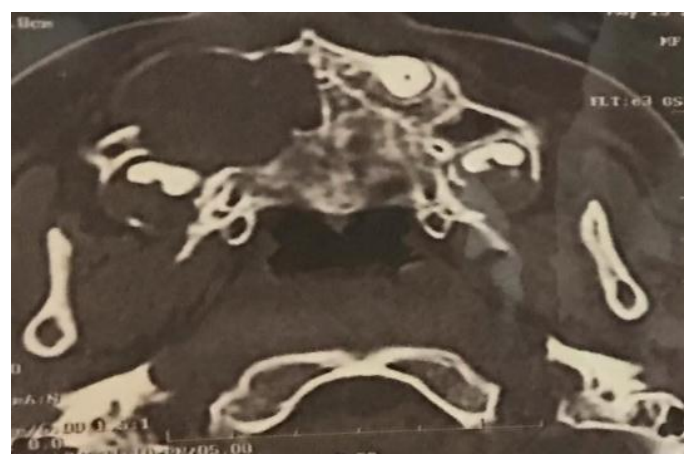

Fig. 2: Axial CT scan of RT Dentigerous cyst

Demographic data for all patients were recorded such as age, sex, residence, cultures, symptoms of sinusitis, etiologic factors, medical and dental reports, surgical or medical therapy, and radiological findings including sinuses and teeth.

Because of its several benefits, including broad and versatile approaches to paranasal sinuses, ESS has been recommended.

Evaluation of outcome:

The evaluation of outcome of ODS treatment was done at the completion of follow-up period, including resolution of symptoms and satisfaction of patients using the Sino-nasal Outcome Test-22 (SNOT-22). It was achieved by asking the patients 22 questions, then the answer listed in a scale from $0-5$, where 0 means no problems with the given symptom and 5 means maximal problems.11 The test was performed to all patients before and after treatment.

Statistical analysis

Data analyses were carried out using SPSS, version 23. The data (with standard deviations [SDs]) are represented as mean values and all statistical tests are 2-tailed. For the data, non-parametric tests were applied. To identify variations among groups, chisquare tests $(\chi 2)$, paired t-test, and student-t-test have been used (according to ANOVA test of variance). The $\mathrm{p}<0.05$ values have been deemed to be statistically significant.

\section{RESULTS}

The research included 25 patients with ODS; 14 males and 11 females represent group 1 . With an average \pm SD of $35.8 \pm 12.69$ years, their ages varied from 18 to 55 years. For comparison, 21 ODS patients treated by dental procedure (12 females and 6 males) aged 19 to 53 years with mean \pm SD of 36.2 \pm 13.17 years represent group 2 .

With regard to the affected teeth; incisors $40 \%$ of ESS group and $42.86 \%$ dental procedures group, canine $36 \%$ of ESS group and $33.3 \%$ of dental group, molar teeth $20 \%$ of ESS group and $14.29 \%$ dental group and wisdom teeth $12 \%$ of ESS group and $9.5 \%$ 
dental group. Dental implant was responsible for $40 \%$ and $47.6 \%$ of ESS group and Dental group, respectively, extraction $(32 \%$ and $33.3 \%)$, respectively, dentigenous cyst $(12 \%$ and $9.5 \%)$ in ESS group and dental group, respectively and radicular cyst (8\% and 4.76\%), in ESS dental group, respectively and dental caries (8\% and $4.76 \%$ ) in ESS and dental groups, respectively (table 1).

\begin{tabular}{|c|c|c|c|c|c|c|}
\hline \multirow{2}{*}{ Gender } & \multicolumn{2}{|c|}{ ESS group } & \multicolumn{2}{|c|}{ Dental group } & \multicolumn{2}{|c|}{ Significance } \\
\hline & No. & $\%$ & No. & $\%$ & $\chi^{2}$ & $\mathrm{P}$ \\
\hline Males & 14 & 56 & 9 & 60 & 2.745 & 0.054 \\
\hline Females & 11 & 44 & 12 & 40 & 1.351 & 0.126 \\
\hline Total & 25 & 100 & 21 & 100 & & \\
\hline Age (years) & Mean & $\pm \mathrm{SD}$ & Mean & $\pm \mathrm{SD}$ & t-test & $\mathrm{P}$ \\
\hline \multirow{3}{*}{$\begin{array}{c}\text { Mean } \pm \text { SD } \\
\text { Range }\end{array}$} & 35.8 & 12.69 & 36.2 & 13.17 & \multirow{3}{*}{0.011} & \multirow{3}{*}{0.491} \\
\hline & Min & Max & Min & $\operatorname{Max}$ & & \\
\hline & 18 & 55 & 19 & 53 & & \\
\hline Teeth affection & No. & $\%$ & No. & $\%$ & $\chi^{2}$ & $\mathrm{P}$ \\
\hline Incisors & 10 & 40 & 9 & 42.86 & 0.644 & 0.389 \\
\hline Canine & 9 & 36 & 7 & 33.33 & 0.872 & 0.174 \\
\hline Molar & 5 & 20 & 3 & 14.29 & 2.124 & 0.094 \\
\hline Wisdom & 3 & 12 & 2 & 9.524 & 1.098 & 0.119 \\
\hline $\begin{array}{c}\text { Dental } \\
\text { pathology }\end{array}$ & No. & $\%$ & No. & $\%$ & $\chi^{2}$ & $\mathrm{P}$ \\
\hline Dental implant & 10 & 40 & 10 & 47.62 & 3.146 & $0.039^{*}$ \\
\hline $\begin{array}{c}\text { Dental } \\
\text { extraction }\end{array}$ & 8 & 32 & 7 & 33.33 & 0.085 & 0.155 \\
\hline $\begin{array}{l}\text { Dentigenous } \\
\text { cyst }\end{array}$ & 3 & 12 & 2 & 9.524 & 0.119 & 0.321 \\
\hline Radicular cyst & 2 & 8 & 1 & 4.762 & 4.037 & $0.016^{*}$ \\
\hline Dental caries & 2 & 8 & 1 & 4.762 & 4.037 & $0.016^{*}$ \\
\hline
\end{tabular}

Table 1: Demographic characteristics of the studied patients.

The asymptomatic patients were $24 \%$ of ESS group and $28.6 \%$ of dental group, while the most common symptoms were rhinorrhea in $16 \%$ and $23.8 \%$ in ESS and dental groups, respectively. Bad odor was found in $40 \%$ and $33.3 \%$, nasal congestion in $20 \%$ and $9.5 \%$, postnasal dripping in $8 \%$ and $4.76 \%$, respectively and gingival swelling in only $4 \%$ of ESS group (Table 2).

\begin{tabular}{|c|c|c|c|c|c|c|}
\hline \multirow{2}{*}{$\begin{array}{c}\text { Symptoms of } \\
\text { sinusitis }\end{array}$} & \multicolumn{2}{|c|}{ ESS group } & \multicolumn{2}{c|}{ Dental group } & \multicolumn{2}{c|}{ Significance } \\
\cline { 2 - 7 } & $\begin{array}{c}\mathrm{N}= \\
25\end{array}$ & $\%$ & $\begin{array}{c}\mathrm{N}= \\
21\end{array}$ & $\%$ & $\chi^{2}$ & $\mathrm{P}$ \\
\hline Asymptomatic & 6 & 24 & 6 & 28.57 & 1.984 & 0.082 \\
\hline Rhinorrhea & 4 & 16 & 5 & 23.81 & 3.739 & $0.028^{*}$ \\
\hline Offensive odor & 10 & 40 & 7 & 33.33 & 2.027 & 0.099 \\
\hline Nasal congestion & 5 & 20 & 2 & 9.524 & 5.182 & $0.002^{*}$ \\
\hline Postnasal dripping & 2 & 8 & 1 & 4.762 & 4.915 & $0.011^{*}$ \\
\hline Gingival swelling & 1 & 4 & 0 & 0.000 & NA & NA \\
\hline
\end{tabular}

Table 2: Common symptoms of the studied patients.

Results of SNOT-22 in ESS group showed 16\%, $24 \%, 32 \%$, and $27 \%$ recorded score $<15,15-30,30$ 45 and $>45$ before treatment, respectively and $72 \%$, $16 \%, 8 \%$, and $4 \%$ after ESS, respectively. They all showed highly statistically significant difference before and after treatment $(\mathrm{P}<0.001)$. Dental group showed 19\%, 23.8\%, 33.3\%, and 23.8\% recorded score $<15,15-30,30-45$ and $>45$ before dental treatment, respectively and $61.9 \%, 19 \%, 14.3 \%$, and $4.76 \%$ after procedure, respectively. There is statistically significant difference $(\mathrm{P}<0.001)$ before and after surgery (table $3 \& 4$ ).

\begin{tabular}{|c|c|c|c|c|c|c|c|c|c|c|}
\hline \multirow{3}{*}{$\begin{array}{c}\text { SNOT- } \\
22\end{array}$} & \multicolumn{5}{|c|}{ ESS group } & \multicolumn{5}{|c|}{ Dental group } \\
\hline & \multicolumn{2}{|c|}{ Before } & \multicolumn{2}{|c|}{ After } & \multirow{2}{*}{$\begin{array}{l}P \text { by } \\
\left(\chi^{2}\right)\end{array}$} & \multicolumn{2}{|c|}{ Before } & \multicolumn{2}{|c|}{ After } & \multirow{2}{*}{$\begin{array}{c}\mathrm{P} \text { by } \\
\left(\chi^{2}\right)\end{array}$} \\
\hline & No. & $\%$ & No. & $\%$ & & No. & $\%$ & No. & $\%$ & \\
\hline $0-<15$ & 4 & 16 & 18 & 72 & $0.000 *$ & 4 & 19.0 & 13 & 61.9 & $0.000^{*}$ \\
\hline $15-<30$ & 6 & 24 & 4 & 16 & $0.001 *$ & 5 & 23.8 & 4 & 19.0 & $0.046^{*}$ \\
\hline $30-<45$ & 8 & 32 & 2 & 8 & $0.000^{*}$ & 7 & 33.3 & 3 & 14.3 & $0.009^{*}$ \\
\hline $45-60$ & 7 & 27 & 1 & 4 & $0.000 *$ & 5 & 23.8 & 1 & 4.76 & $0.000^{*}$ \\
\hline Total & 25 & 100 & 25 & 100 & & 21 & 100 & 10 & 100 & \\
\hline
\end{tabular}

Table 3: SNOT-22 questionnaire before and after treatment

\begin{tabular}{|c|c|c|c|c|}
\hline $\begin{array}{c}\text { Before } \\
\text { treatment }\end{array}$ & $\begin{array}{c}\text { ESS } \\
\text { group }\end{array}$ & $\begin{array}{c}\text { Dental } \\
\text { group }\end{array}$ & $\begin{array}{c}\mathrm{t}- \\
\text { test }^{\#}\end{array}$ & $\mathrm{P}$ \\
\hline Mean $\pm \mathrm{SD}$ & $\begin{array}{c}38.75 \pm \\
9.56\end{array}$ & $\begin{array}{c}37.93 \pm \\
11.3\end{array}$ & 0.002 & 0.831 \\
\hline $\begin{array}{c}\text { After } \\
\text { treatment }\end{array}$ & & & & \\
\hline Mean $\pm \mathrm{SD}$ & $\begin{array}{c}15.7 \pm \\
18.12\end{array}$ & $\begin{array}{c}28.42 \pm \\
21.7\end{array}$ & 5.644 & $0.002^{*}$ \\
\hline t-test & 12.256 & 3.825 & & \\
\hline P value & $0.000^{*}$ & $0.039^{*}$ & & \\
\hline
\end{tabular}

Table 4: Improvement of SNOT-22 questionnaire after treatment.

\# Independent t-test, * $\mathrm{P}<0.05=$ significant.

Improvement of SNOT-22 score was observed from $38.75 \pm 9.56$ before treatment to $15.7 \pm 18.12$ after ESS ( $\mathrm{p}<0.001$ ), and from $37.93 \pm 11.3$ to $28.42 \pm$ 21.7 after dental procedure $(\mathrm{P}=0.039)$, as shown in table (4). It was observed that the early ESS intervention for ODS is the key for successful outcome (figure. 1).

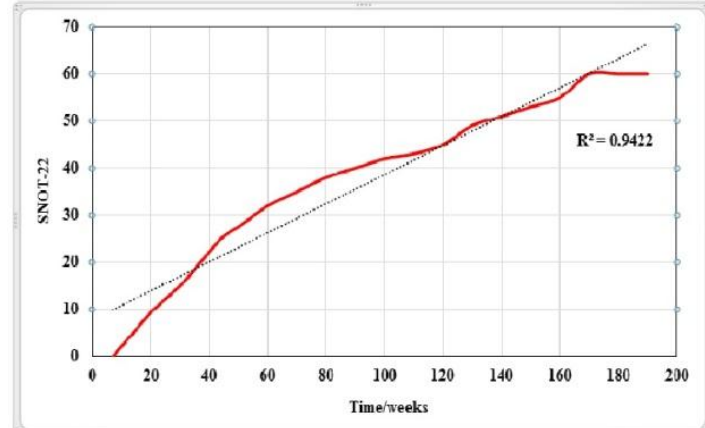

Fig. 3: Correlation coefficient (r) between ESS timing (weeks) and SNOT-22 score. The figure shows statistically positive correlation between ESS timing and SNOT-22 score $(r=0.9707, p=0.000)$. This indicated that SNOT-22 increased late endoscopic sinus surgery, so, good outcome results was observed in early ESS as the trendline (dotted) showed.

\section{DISCUSSION}

A combination of medical, dental, and sinus surgical treatment is required for successful treatment of ODS. ${ }^{12}$ While dental surgery has been emphasized as the primary modality of treatment for ODS in several studies, there is recent evidence that ESS alone can be an effective treatment strategy. ${ }^{1}$ Wang et al. ${ }^{12}$ stated that for each patient, ESS should be applied to treat odontogenic sinusitis (OS). 
In this study, 25 patients referred for treatment of odontogenic sinusitis that we performed ESS for them with mean age of $35.8 \pm 12.69$ years. The outcome was compared with 21 ODS patients treated by dental procedure with mean age of $36.2 \pm 13.17$ years. However, OS was previously reported between ages 40-60 years old. ${ }^{13}$

Our study showed variations of the teeth of etiology, incisors were the commonest cause for ODS as they were $40 \%$ in ESS group and $42.68 \%$ in dental group followed by canine, then the molar and wisdom teeth. A study by Kim et al. ${ }^{14}$ found that the second molar with an average duration of symptoms of 4.31 months is the most commonly implanted tooth.

In our study, the etiology of ODS was attributed to dental implant in $40 \%$ of ESS cases and $47.6 \%$ of dental group, followed by teeth extraction in $32 \%$ \& $33.3 \%$, then, dentigenous cyst in $12 \%$ \& $9.5 \%$, and both radicular cyst and caries in $8 \%$ \& $4.76 \%$, respectively. Various odontogenic pathologies may cause ODS, as pulpitis, oroantral fistulas, periodontitis, periapical lesions, or sinus foreign bodies that related to dental procedures. ${ }^{15}$ Periapical lesions, however, are substantially correlated with sinus mucosal thickening and ODS. ${ }^{16}$

In Japan, it is becoming rare for untreated dental diseases to trigger ODS because of increased awareness of personal hygiene. ${ }^{17}$ Alternatively, dental therapy, especially root canal therapy, that is, endodontics, has already been given to most teeth that trigger ODS. ${ }^{16}$

Both causative teeth may be preserved on their own with antibiotic therapy (endodontic-treated teeth, i.e. root-canal-treated teeth with apical lesions). ${ }^{18}$

In sufferers who lack initial medical and dental therapy, endoscopic sinus surgery has been recommended. ${ }^{9}$ Several research have demonstrated excellent findings in ESS and dental surgery, whereas the ideal management sequence is not apparent. ESS is reported as the preferred surgical therapy for ODS. ${ }^{19}$ An oral approach to the sinus is needed, however; authors appear to favor less intrusive methods like the antral retriever ${ }^{20}$ or the formation of a bony window pedicled to the membrane of Schneider. ${ }^{21}$

A retrospective study of 43 patients with ODS demonstrated $52 \%$ of patients improved by dental and medical therapy, while $48 \%$ required ESS. Among these, $14 \%$ of patients needed both dental and ESS interventions. ${ }^{10}$ Kim et al. ${ }^{14}$ had 19 patients directly treated for ODS due to a dental implant. Just $21 \%$ of them were treated medically successfully, whereas $79 \%$ needed ESS.

Another study examining ODS in patients with dental implants stated that ESS with culture and antibiotic therapy for sensitivity may be an important therapeutic technique for disease resolution. ${ }^{22}$ In this study with intact dental implants, all were successfully treated at an average follow-up of 18 months without elimination of the implant involved.

Wang et al. ${ }^{12}$ have identified the patients receiving therapy for ODS had complete resolution, $33 \%$ resolved by ESS alone and 33\% required ESS and dental surgery together, $10 \%$ solved by dental surgery alone and another $10 \%$ solved by ESS following dental treatment failure, while $10 \%$ resolved spontaneously by medical treatment alone. So, a substantial number of patients have been successfully treated with ESS alone (one third) and after dental procedure (10\%), the researchers recommended that dental surgery must stay the firstline ODS therapy because it represents a target infection source followed by ESS if needed.

In order to enhance sinusitis early on, if the antibiotics did not enhance OS, we preferentially carried out ESS first prior the dental treatment. Improvement of SNOT-22 score in the present study was changed from $38.75 \pm 9.56$ before treatment to $15.7 \pm 18.12$ after ESS ( $\mathrm{p}<0.001$ ), and from $37.93 \pm$ 11.3 to $28.42 \pm 21.7$ after dental procedure $(\mathrm{P}$ $=0.039$ ). There is more improvement of the score (lower SNOT-22) in ESS compared to dental treatment. In agreement with these results, Jiam et $\mathrm{al}^{22}$ had followed up their patients up to 39 months and stated lower post-ESS SNOT-22 score (32 of 110 patients) relative to the SNOT-22 pre-dental score (14 of 110 patients). Sinus surgery following the sinus lift procedure resulting in an 18-point reduction in the SNOT-22 score (95\% confidence interval, 432) relative to the SNOT-22 score acquired at the preoperative appointment, $\mathrm{p}=0.02$, a minimal clinically significant variation in SNOT-22.

Recent research by Craig et al. ${ }^{23}$ and Yoo et al. ${ }^{24}$ have shown that upfront ESS is just as successful as dental therapy, and that with primary ESS, more patients get symptom resolution quicker. They found that, relative to primary dental therapy, primary ESS led in a quicker resolution of SNOT-22, sinusitis symptoms, and endoscopic results in ODS patients. It is clear from the viewpoint of sinusitis that sinusitis enhances more rapidly with ESS than with dental therapy. ${ }^{24}$ From a pathophysiological viewpoint, however, first removing the causative pathological tooth might be more rational. Furthermore, unnecessary surgery may be avoided if sinusitis is entirely treated by dental treatment alone, thus minimizing the pain and perioperative risk that can be triggered by ESS and minimizing the total medical costs incurred. In addition, some patients in the Craig et al. ${ }^{23}$ study in whom ODS was induced following tooth extraction should be excluded from dental treatment because ESS was the only choice because there was no treatment for the tooth. They added that the ODS burden is high, primary ESS should be prescribed, followed as required by close dental follow-up and therapy.

Also, the same findings by the very recent study by Lin and Chen ${ }^{25}$ as they found decrease in SNOT-22 score from mean of 37.5 to 13.5 post-ESS which was parallel to our results. Another recent study by Sato et al. ${ }^{18}$ found in cone beam CT scans and postoperative nasal endoscopy, the natural ostium and the sinus membranous parts were expanded and the complexes of the ostiomeatal stayed broadly open. The drainage and ventilation of ODS were successfully restored during $\sim 36$ months of 
follow-up. Recurrence was not imminent following the primary ESS for ODS.

On the other hand; A 2018 position statement on maxillary sinusitis of endodontic origin was issued by the American Academy of Endodontics, indicating that dental therapy should be done first, followed by ESS only if necessary. ${ }^{8}$ Also, the case series of 21 ODS patients has been reported by Longhini and Ferguson ${ }^{26}$. After dental removal, nineteen of these patients responded. Therefore, they suggested that ESS should be accompanied by dental treatment.

Other indirect evidence indicating that ESS should be accompanied by dental therapy when treating ODS appears to come from studies showing that unrecognized odontogenic pathology can contribute to the failure of $\mathrm{ESS}^{27}$ However, symptoms of sinusitis were not discussed by the researchers; heterogeneous groups of patients made it hard to make conclusions about the correct timing of therapy. An optimal treatment sequence has not been suggested by studies since no studies have analyzed the time course of ODS resolution following dental therapy and $\mathrm{ESS}^{23}$

Yoo et al. ${ }^{24}$ as well as Longhini and Ferguson ${ }^{26}$ add another factor for ESS to be performed first that is smoking. Smokers were more prone to need ESS following the failure of dental treatment since smoking activates the nasal mucosa, raises the resistance of intranasal air, and induces physiological responses like nasal congestion and rhinorrhea. ${ }^{28}$

The Oroantral Fistula (OAF) following tooth extraction is another point of concern. If the ESS is postponed, leading to the development of dental caries and bone destruction, the likelihood of permanent $\mathrm{OAF}$ occurring following extraction will increase. If, under active inflammation, the tooth is removed, OAF can also increase. Therefore, if the dental caries and the bony destruction at the maxillary floor are serious, prior tooth removal, the ESS can be performed first to control inflammation.

When sinus ventilation and drainage are effectively restored after ESS, and most causative teeth are preserved, apical lesions and odontogenic infection can lead to silent chronic lesions treated by antibiotic treatment alone. ${ }^{18}$ This is why ESS is strongly recommended for surgery involving unsolvable ODS prior to causative tooth extraction or dental treatment. Craig et al. ${ }^{23}$ endorse this idea that for symptomatic ODS, ESS should be considered firstline treatment, accompanied if appropriate by dental treatment. That is because primary ESS resulted in a faster resolution of symptoms of sinusitis, SNOT-22, and endoscopy results that were also observed in our study.

\section{CONCLUSION}

An early ESS of ODS is a clue for a successful treatment outcome, particularly in patients' sufferings sever unresolved sinusitis. So, it is recommended that primary ESS is first to be performed, followed by dental treatment, which is the ideal protocol for management of ODS.

\section{REFERENCES}

1. Little RE, Long CM, Loehrl TA, Poetker DM. Odontogenic sinusitis: A review of the current literature. Laryngoscope Investig Otolaryn-gol. 2018;3(2):110-4. Doi: 10.1002/lio2.147.

2. Puglisi S, Privitera S, Maiolino L, et al. Bacteriological findings and antimicrobial resistance in odontogenic and non-odontogenic chronic maxillary sinusitis. J Medical Microbiology. 2011; 60: 1353-9. Doi: 10.1099/jmm.0.031476-0.

3. Mehra P, Jeong D. Maxillary sinusitis of odontogenic origin. Curr Infect Dis Rep. 2008; 10(3): 205-10. Doi: 10.1007/s11908-008-0034-7.

4. Arias-Irimia O, Barona-Dorado C, Santos-Marino JA, Martinez-Rodriguez N, Martinez-Gonzalez JM. Meta-analysis of the etiology of odontogenic maxillary sinusitis. Med Oral Patol Oral Cir Bucal. 2010; 15:70-3. Doi: 10.4317/medoral.15.e70.

5. Troeltzsch M, Pache C, Troeltzsch M, et al. Etiology and clinical characteristics of symptomatic unilateral maxillary sinusitis: A review of 174 cases. $J$ Craniomaxillofac Surg. 2015; 43: 1522-9. Doi: 10.1016/j.jcms. 2015.07.021.

6. Shahbazian M, Vandewoude C, Wyatt J, Jacobs R. Comparative assessment of periapical radiography and CBCT imaging for radiodiagnostics in the posterior maxilla. Odontology. 2015;103(1):97-104. doi: 10.1007/s10266-013-0144-z.

7. Rosenfeld RM, Andes D, Bhattacharyya N, et al. Clinical practice guideline: Adult sinusitis. Otolaryngol Head Neck Surg. 2007; 137(3): S1-S31. Doi: 10.1016/j.otohns.2007.06.726.

8. Tataryn RW, Lewis MJ, Horalek AL, Thompson CG, Cha BY, Pokony AT. Maxillary Sinusitiss of Endodontic Origin: The American Academy of Endodontics Position Statement 2018; 1-11.

9. Fadda GL, Berrone M, Crosetti E, Succo G. Monolateral sinonasal complications of dental disease or treatment: When does endoscopic endonasal surgery require an intraoral approach: Acta Otorhino Italica. 2016; 36:300-309. Doi: 10.14639/0392-100X-904.

10. Mattos JL, Ferguson BJ, Lee S. Predictive factors in patients undergoing endoscopic sinus surgery for odontogenic sinusitis. Int Forum Allergy Rhinol. 2016; 6:697-700. Doi: 10.1002/alr.21736.

11. Yeolekar A, Dasgupta K, Khode S, Joshi D, Gosrani N. A Study of SNOT 22 Scores in Adults with no Sinonasal Disease. J Rhino-laryngo Oto. 2013; 1 Doi: 10.12970/2308-7978.2013.01.01.2.

12. Wang KL, Nichols BG, Poetker DM, Loehrl TA. Odontogenic sinusitis: a case series studying 
diagnosis and management. Int Forum Allergy Rhino.l 2015; 5:597-601. Doi: 10.1002/alr.21504.

13. Zirk M, Dreiseidler T, Pohl M, et al. Odontogenic sinusitis maxillaris: A retrospective study of 121 cases with surgical intervention. J Craniomaxillofac Surg. 2017; 45: 520-5. Doi: 10.1016/j.jcms.2017.01. 023 .

14. Kim SJ, Park JS, Kim HT, Lee CH, Park YH, Bae JH. Clinical features and treatment outcomes of dental implant-related paranasal sinusitis: A 2-year prospective observational study. Clin Oral Implants Research. 2016; 27:100-4. Doi: 10.1111/clr.12570.

15. Taschieri S, Torreta S, Corbella $S$, et al Pathophysiology of sinusitis of odontogenic origin. $J$ Investig Clin Dent. 2017; 8:1-7. Doi: 10.1111/jicd.12202.

16. Penarrocha-Oltra S, Soto-Penaloza D, Bagan-Debon L, Bagan JV, Penarrocha-Oltra D. Association between maxillary sinus pathology and odontogenic lesions in patients evaluated by cone beam computed tomogram-phy. A systematic review and meta-analysis. Med Oral Pathol Oral Cir Bucal. 2020; 25: e34-e48. Doi: 10.4317/medoral.23172.

17. Sato K. Odontogenic maxillary sinusitis caused by dental restoration. Nihon Jibiinkoka Gakkai Kaiho. 2014; 117:809-14. Doi: 10.3950/jibiinkoka.117.809.

18. Sato K, Chitose SI, Sato K, Sato F, Ono T, Umeno H. Histopathology of maxillary sinus mucosa with odontogenic maxillary sinusitis. Laryngoscope Investig Otolaryngol. 2020; 5(2):205-9. doi:10.1002/lio2.376.

19. Saibene, Alberto Maria et al. Odontogenic rhinosinusitis and sinonasal complications of dental disease or treatment: prospective validation of a classification and treatment protocol. Head and Neck Surgery vol. 2019; 276(2): 401-6. doi:10.1007/s00405-018-5220-0.

20. Mantovani M, Pipolo C, Messina F, Felisati G, Torretta S, Pignataro L. Antral retriever and displaced dental implants in the maxillary sinus. $J$ Craniofac Surg. 2011;22(6):2275-7. doi: 10.1097/SCS.0b013e3182327125.

21. Biglioli F, Chiapasco M. An easy access to retrieve dental implants displaced into the maxillary sinus: the bony window technique. Clin Oral Implants Res. 2014;25(12):1344-51. doi: 10.1111/clr.12276.

22. Jiam NT, Goldberg AN, Murr AH, Pletcher SD. Surgical treatment of chronic rhino-sinusitis after sinus lift. Am J Rhinol Allergy 2017;31:271-5. Doi: 10.2500/ajra.2017.31. 4451.

23. Craig J, McHugh C, Griggs Z, Peterson E. Optimal timing of endoscopic sinus surgery for odontogenic sinusitis. Laryngosc. 2019; 129:1976-83. doi: 10.1002/Lary.28001.

24. Yoo BJ, Jung SM, Lee HN, Kim HG, Chung JH, Jeong JH. Treatment Strategy for Odontogenic Sinusitis. American Journal of Rhinology \& Allergy 2020; 0(0) 1-7.

25. Lin YH, Chen WC. Clinical outcome of endonasal endoscopic prelacrimal approach in managing different maxillary pathologies. PeerJ. 2020;8:e8331. doi:10.7717/peerj.8331.

26. Longhini AB, Ferguson BJ. Clinical aspects of odontogenic maxillary sinusitis: a case series. Int Forum Allergy Rhinol. 2011; 1:409-415. Doi: 10.1002/alr.20058.

27. Albu S, Baciut M. Failures in endoscopic surgery of the maxillary sinus. Otolaryngol Head Neck Surg 2010; 142:196-201.

Doi: 10.1016/j.otohns.2009.10.038.

28. Reh DD, Higgins TS, Smith TL. Impact of tobacco smoke on chronic rhinosinusitis: a review of the literature. Int Forum Allergy Rhinol. 2012;2(5):3629 